\title{
Effects in the Short-Term of Combining an Eco- Friendly Slag Cement and Several Lightweight Aggregates in Relation to the Microstructure and Water Ingress Ability of Mortars ${ }^{+}$
}

\author{
José Marcos Ortega ${ }^{1, *}$, Fernando G. Branco ${ }^{2}$ and Luís Pereira ${ }^{2}$ \\ 1 Departamento de Ingeniería Civil, Universidad de Alicante, Ap. Correos 99, 03080 Alacant/Alicante, Spain \\ 2 ISISE, Department of Civil Engineering, University of Coimbra, R. Luís Reis Santos, 3030-788 Coimbra, \\ Portugal; fjbranco@dec.uc.pt (F.G.B.); lfmpereira@uc.pt (L.P.) \\ * Correspondence: jm.ortega@ua.es; Tel.: +34-96-5903-400 \\ + Presented at 1st International Electronic Conference on Applied Sciences, 10-30 November 2020; Available \\ online: https://asec2020.sciforum.net/.
}

Published: 10 November 2020

\begin{abstract}
Improving the sustainability of the construction sector is now a major issue. In order to reach more eco-friendly buildings and structures, the use of cements which incorporate additions as clinker replacement has reached a great development. Furthermore, the use of lightweight aggregates has a great interest regarding the sustainability of construction industry. In this research, the effects at early hardening ages of combining a sustainable cement with high content of ground granulated blast furnace slag (type CEM III/B) and different lightweight aggregates in the microstructure and durability of mortars have been studied. In these mortars, $50 \%$ of the sand volume has been replaced by lightweight aggregates, such as natural cork, expanded cork and expanded clay. Reference mortars with an ordinary Portland cement (type CEM I) have also been prepared, as well as mortars without lightweight aggregates. The samples were kept submerged in water until the testing age. The microstructure has been studied using mercury intrusion porosimetry and scanning electron microscopy. Regarding the durability influencing parameters, water absorption has been analyzed. According to the results obtained, the incorporation of slag improved the overall performance of the mortars with the studied lightweight aggregates.
\end{abstract}

Keywords: ground granulated blast furnace slag; lightweight aggregates; natural cork; expanded cork; expanded clay; microstructure; durability; water ingress; eco-friendly cement

\section{Introduction}

Nowadays, improving the sustainability of the construction sector in general is a major issue. In order to reach more eco-friendly buildings and structures, the use of cements which incorporate additions as clinker replacement has reached a great development [1]. Among these additions, it is important to highlight the ground granulated blast furnace slag, which produces a finer pore network of cement-based materials [2] and improves some of their service properties, such as the resistance to chloride ingress [3]. On the other hand, the use of lightweight aggregates has also a great interest regarding the sustainability of construction industry. Among other advantages, they lead to a lessening in the density of cement-based materials, increasing their thermal resistance, and producing a reduction of dead loads in the construction elements. Today, the development of new lightweight aggregates is an important topic of research, in order to complement or even improve the classical ones, such as expanded clay. Among them, several researches $[4,5]$ have been developed, exploring the potential of cork granulates as lightweight aggregate. Furthermore, the combination of cements 
with additions with these new lightweight aggregates would open a promising field of study for obtaining more eco-friendly cement-based materials for specific applications.

Therefore, the main aim of this work is to study the effects at early hardening ages in the microstructure and water absorption of mortars, in which a sustainable cement with high content of ground granulated blast furnace slag and different lightweight aggregates were combined. Two novel aggregates such as natural cork and expanded cork have been studied, as a well as a traditional one like expanded clay.

\section{Materials and Methods}

\subsection{Materials and Sample Preparation}

The materials studied in this research were mortars, in which different commercial cements and lightweight aggregates were combined. The cements used were an ordinary Portland cement CEM I 42.5 R (European standard EN 197-1[6]) and sustainable cement type III/B 32.5 N/SR [6] with high content of ground granulated blast furnace slag $(70 \%)$. Regarding the lightweight aggregates, natural cork, expanded cork and expanded clay were studied. In the analyzed mortars, $50 \%$ of the volume of the sand has been replaced by and equivalent volume of the abovementioned lightweight aggregates. Furthermore, reference mortars without incorporation of these aggregates were also prepared.

The mortars produced with CEM I $42.5 \mathrm{R}$ cement were designed as 1REF (without lightweight aggregates), 1ECK (with expanded cork), 1NCK (with natural cork) and 1ECL (with expanded clay). On the other hand, the different mortars made with sustainable cement type III/B 32.5 N/SR were named as 3REF (without lightweight aggregates), 3ECK (with expanded cork), 3NCK (with natural cork) and 3ECL (with expanded clay). The water to cement ratio was 0.5 (in weight) and the aggregate to cement ratio was 3:1 (in weight) for the reference series. In lightweight series, partial replacement of the natural sand by an equal volume of the studied aggregate was carried out.

Prismatic samples with dimensions $4 \mathrm{~cm} \times 4 \mathrm{~cm} \times 16 \mathrm{~cm}$ were prepared. They were de-moulded after $24 \mathrm{~h}$ of setting. Then, they were stored submerged in water at $20^{\circ} \mathrm{C}$ until the testing age, which was 28 hardening days.

\subsection{Experimental Techniques}

The microstructure of the mortars was characterized using mercury intrusion porosimetry and scanning electron microscopy (SEM). The mercury intrusion porosimetry test was performed using a porosimeter model Poremaster-60 GT of the manufacturer Quantachrome Instruments (Boynton Beach, FL, USA). The samples were oven dried at $50{ }^{\circ} \mathrm{C}$ for $48 \mathrm{~h}$ prior to the test. The results analyzed in this research were total porosity and pore size distribution. Two measurements were made on each type of mortar. The pieces tested of each mortar were taken from the prismatic samples. In order to complete the microstructural study of the mortars, SEM images were taken in pieces obtained from prismatic specimens. The scanning electron microscope used was a Hitachi model S3000N (Krefeld, Germany). Finally, as durability parameter, the absorption after immersion was obtained following the procedure included in the ASTM Standard C642-06 [7]. Six pieces removed from prismatic samples were tested for each kind of mortar studied.

\section{Results and Discussion}

The total porosities noted at 28 hardening days, obtained using mercury intrusion porosimetry, for the analyzed mortars are depicted in Figure 1. As can be observed in that figure, for specimens made using CEM I $42.5 \mathrm{R}$ (CEM I from now on), the lowest total porosity was obtained for 1REF specimens, as can be expected, because they did not incorporate lightweight aggregates, which are more porous than sand. The highest total porosity of mortars prepared with CEM I corresponded to those with expanded cork (1ECK series), followed by specimens which incorporate natural cork (1NCK series). In the case of specimens made with expanded clay (1ECL series), the total porosity observed was lower than that noted for samples with expanded and natural cork, although it was greater than the value of this parameter obtained for 1 REF mortars. 


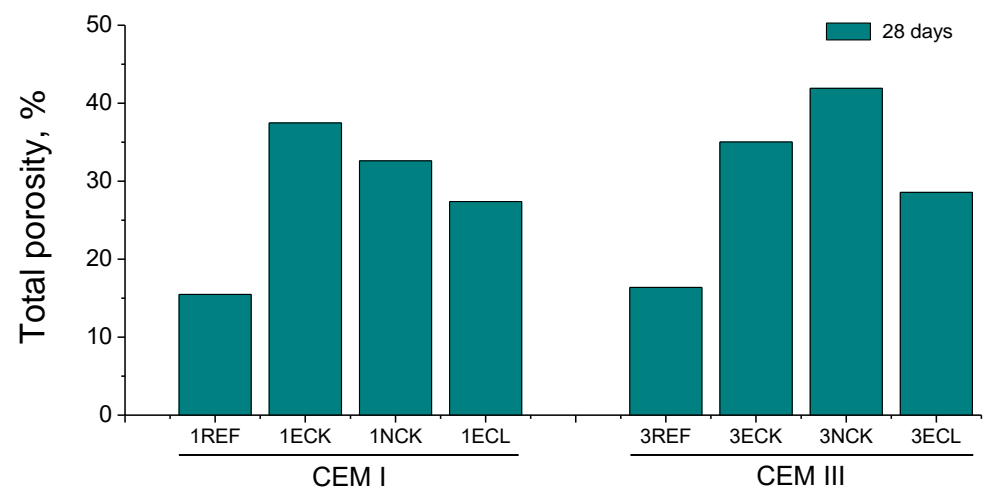

Figure 1. Total porosity results obtained for the studied mortars. CEM I refers to mortars made using cement CEM I 42.5 R and CEM III refers to mortars prepared using cement III/B 32.5 N/SR.

In relation to mortars made with slag cement III/B 32.5 N/SR (CEM III from now on), as happened with CEM I specimens, the lowest total porosity was noted for those without lightweight aggregates (3REF series). As has been previously mentioned, this is due to the fact that this series was prepared only with sand without lightweight aggregates, which are more porous, so their presence would entail a larger total porosity of the global microstructure of the mortar. For slag cement mortars with cork aggregates, the greatest value of this parameter was noted for those which incorporated natural cork (3NCK series), being slightly lower the total porosity obtained in specimens with expanded cork (3ECK series). Lastly, the mortars with slag and expanded clay (3ECL series) showed a total porosity between the values obtained for 3REF and 3ECK ones.

On the other hand, comparing the influence of the two cements for each one of the studied aggregates, it has been observed that for mortars without lightweight aggregates, the total porosity of 3REF was scarcely high than for 1REF. Regarding the specimens with expanded clay, those produced with slag cement (3ECK) showed smaller total porosity than 1ECK ones. For this lightweight aggregate, it seems that the use of cement with high content of slag had a more evident beneficial effect in relation to total porosity, at least in the short-term. On the other hand, the specimens with natural cork had higher total porosity when CEM III is used (3NCK series) in comparison with those made with CEM I cement (1NCK series). With respect to mortars with expanded clay, the total porosity at 28 hardening days was very similar for both 1ECL and 3ECL. However, it is known that the effects of slag hydration are extended in the long term [2], so a greater microstructure development of mortars made with CEM III at later hardening ages is expected.

The pore size distributions obtained for the studied mortars are represented in Figure 2. For samples prepared using CEM I, the most refined microstructure, with higher proportion of smaller pores, was observed for reference mortars (1REF) and with expanded clay (1ECL series). In relation to mortars with this cement and cork as aggregate, a greater refinement of the microstructure was noted for natural cork (1NCK specimens) compared to expanded cork (1ECK samples), although the pore network of both series showed higher percentage of larger pores (diameters higher than $1 \mu \mathrm{m}$ ) respect to 1 REF and 1ECL samples.

The pore structure of mortars made with slag cement CEM III was more refined for 3REF series. As has been explained for total porosity, this could be explained because this series did not incorporate lightweight aggregates. The mortars with slag cement and expanded clay (3ECL specimens) showed a similar proportion of pores lower than $1 \mu \mathrm{m}$ compared to 3REF ones, however the 3ECL mortars had a less percentage of pores with diameters slower than $100 \mathrm{~nm}$. For samples with cork, 3NCK mortars presented a more refined microstructure, although the relative volume of pores with sizes smaller than $100 \mathrm{~nm}$ was slightly greater for 3ECK specimens, but their global volume of total pores in the ranges $<10 \mathrm{~nm}, 10-100 \mathrm{~nm}$ and $100 \mathrm{~nm}-1 \mu \mathrm{m}$ was lower compared to 3NCK ones. In general, if the pore size distributions for each aggregate studied are compared, as a function of the cement type, it can be observed that the microstructure was overall more refined for 
specimens which incorporate slag cement CEM III. It is very noticeable the presence of a high proportion of pores lower than $100 \mathrm{~nm}$ in mortars with this cement, highlighting the rise of the relatively volume of pore range $<10 \mathrm{~nm}$. This could be due to the beneficial effect of the slag addition in the development of the microstructure [2]. The slag hydration led to the formation of new solid phases which would progressively fill the pores of the material, producing a finer microstructure [8], as can be observed in the results obtained.

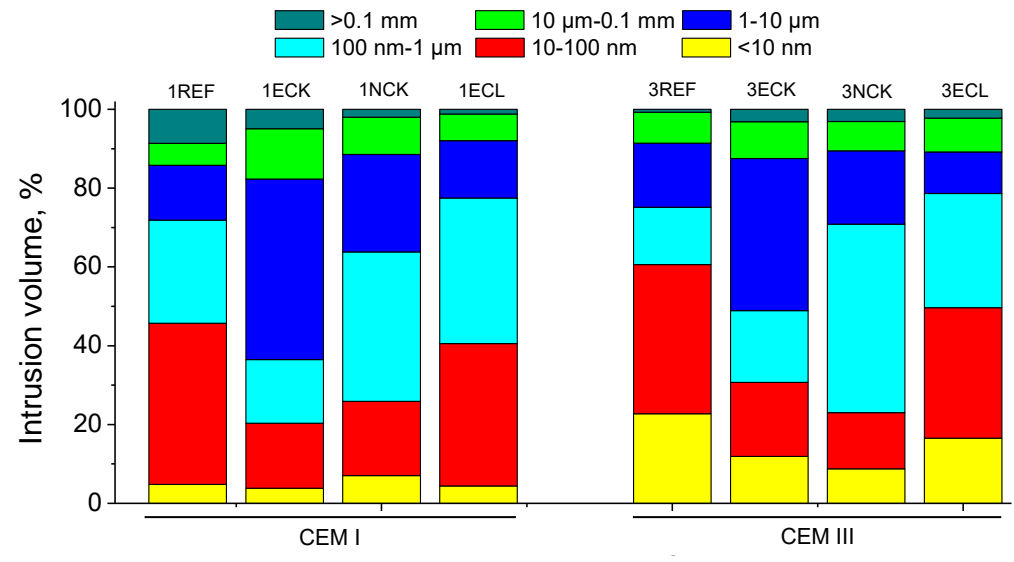

Figure 2. Pore size distributions for the different types of mortars analyzed.

In Figures $3 a, b$ and $4 a, b$ SEM images of the mortars made using CEM I can be observed, and in Figures $5 \mathrm{a}, \mathrm{b}$ and $6 \mathrm{a}, \mathrm{b}$ are included SEM images of the mortars prepared with CEM III.

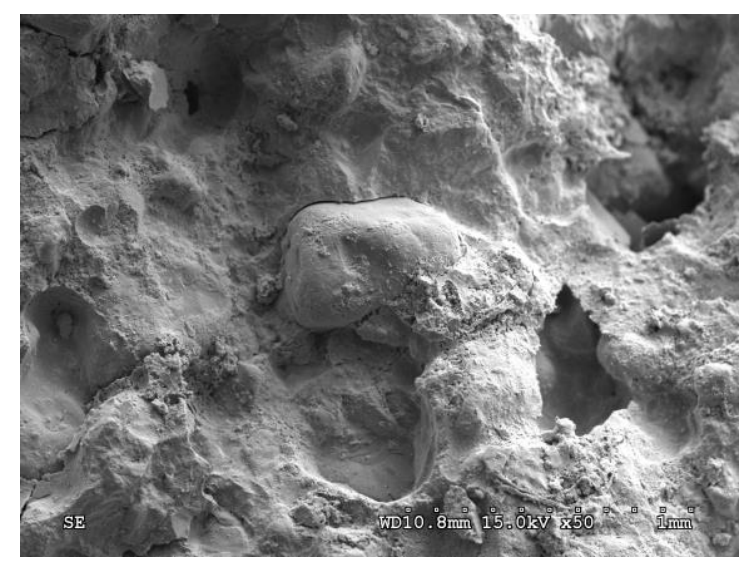

(a)

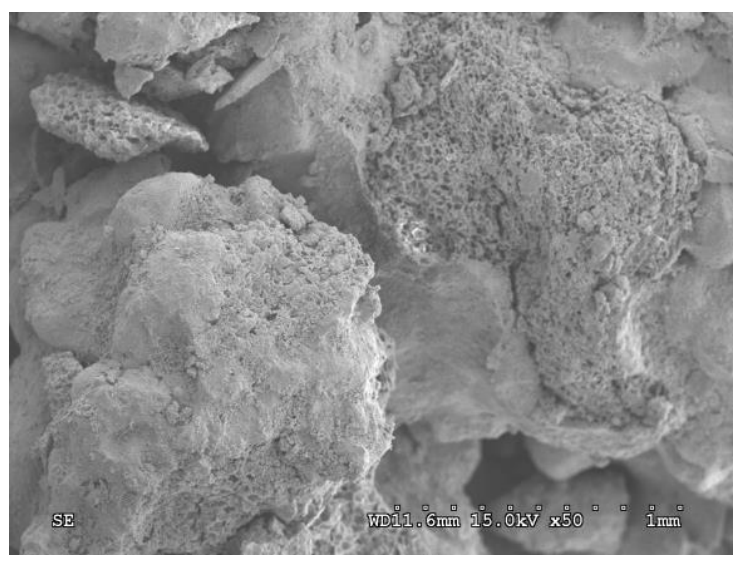

(b)

Figure 3. (a) SEM image of 1 REF mortar; (b) SEM image of 1ECK mortar.

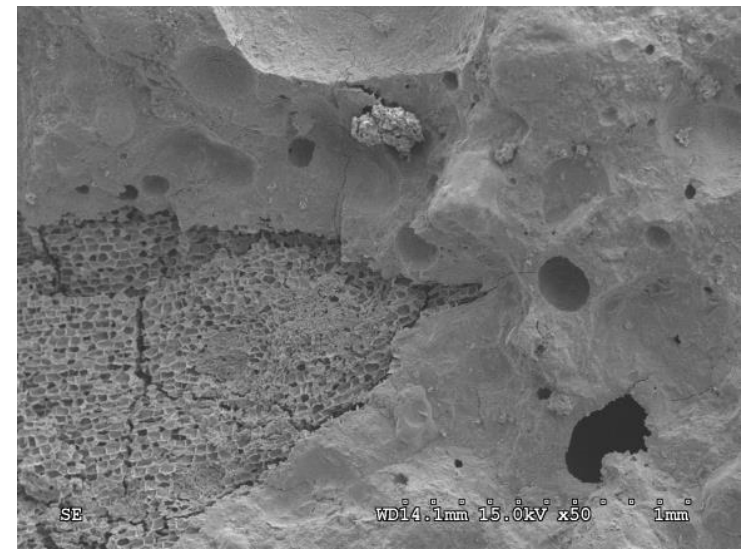

(a)

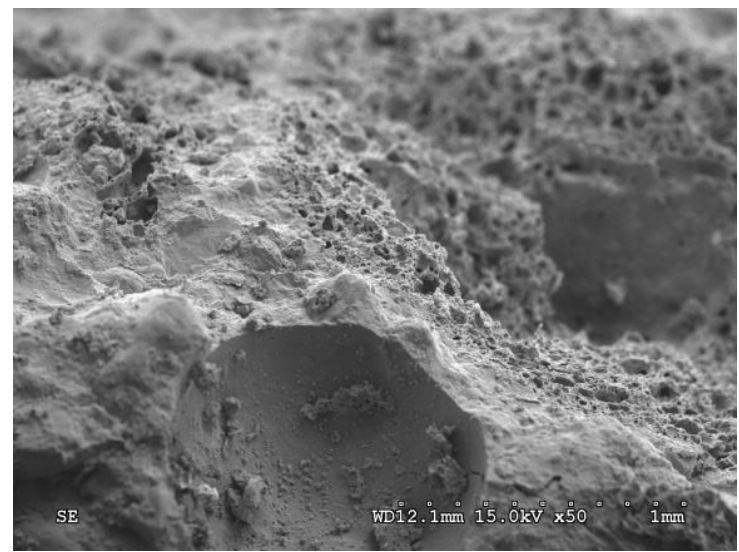

(b)

Figure 4. (a) SEM image of 1NCK mortar; (b) SEM image of 1ECL mortar. 


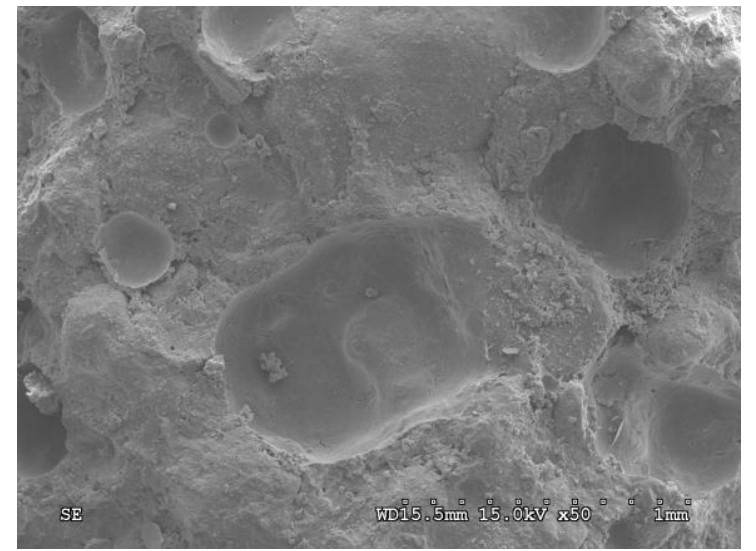

(a)

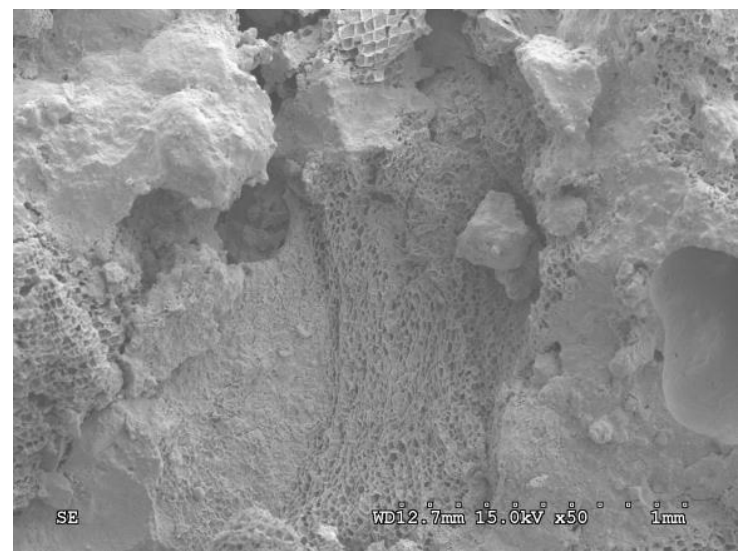

(b)

Figure 5. (a) SEM image of 3REF mortar; (b) SEM image of 3ECK mortar.

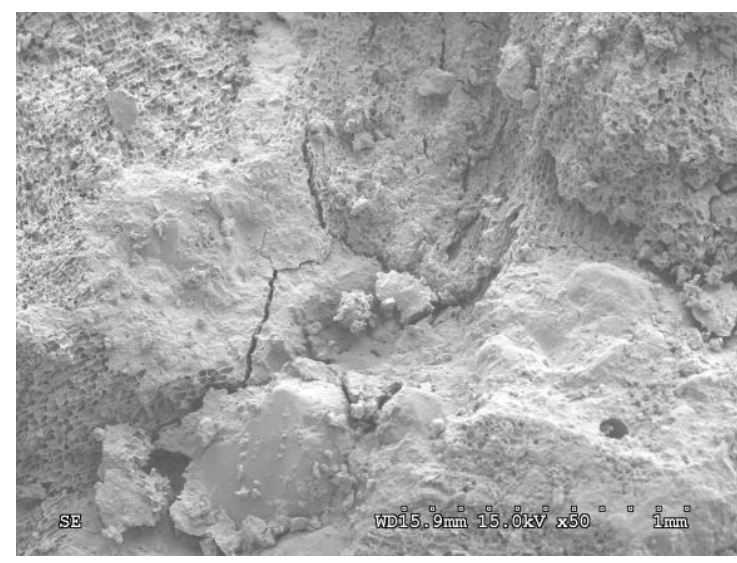

(a)

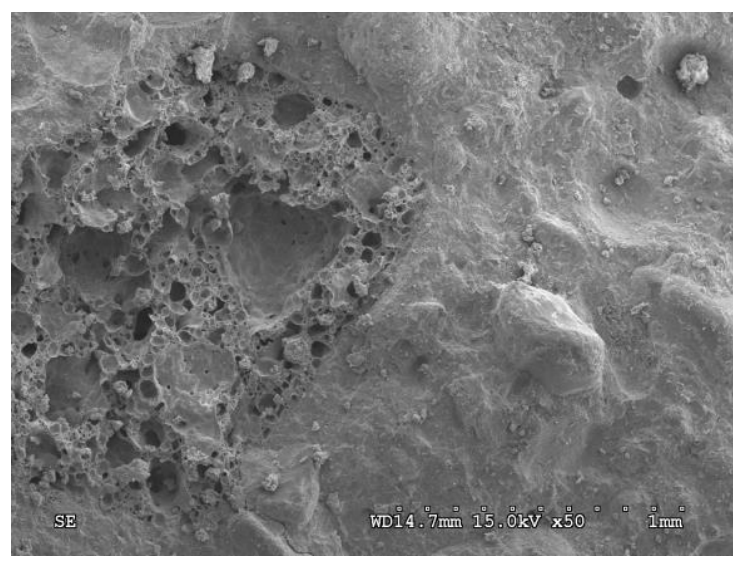

(b)

Figure 6. (a) SEM image of 3NCK mortar; (b) SEM image of 3ECL mortar.

As can be observed in the SEM images, the microstructure was more compact in specimens without lightweight additions (1REF and 3REF series). For mortars with expanded clay, the cement matrix seemed less porous for those with slag cement (3ECL) compared to 1ECL ones, clearly showing that the largest pores were in the aggregate. In the SEM images of the specimens with expanded and natural cork, it was observed that these aggregates presented finer pores but in larger number, and the cement matrix in those specimens seemed less refined when compared to reference and expanded clay ones. Furthermore, for both cork aggregates, it can be observed that the porous network, especially the cement matrix was more compact and refined when slag cement was used. These results were generally in keeping with those obtained using mercury intrusion porosimetry.

Finally, the results of water absorption after immersion are represented in Figure 7 . As can be expected from previously discussed parameters, the lowest values of this parameter are noted for references specimens without lightweight aggregates, independently of the cement type used. The highest absorption corresponded to expanded cork samples, followed by natural cork ones. For expanded clay mortars, their values of water absorption after immersion were between those noted for reference and cork specimens. In general, mortars made using slag cement showed lower values of this parameter for the same aggregate. Again, these results are in accordance with those discussed in the microstructure characterization. 


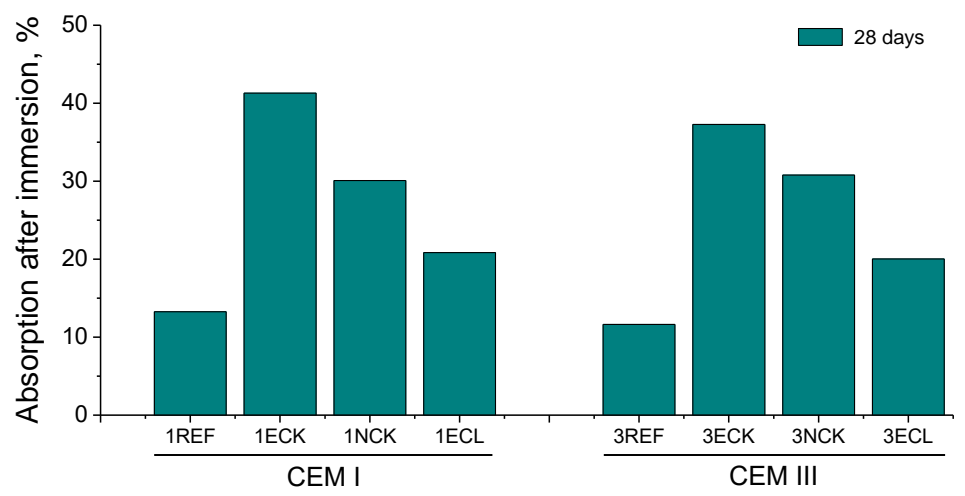

Figure 7. Absorption after immersion for the mortars studied.

\section{Conclusions}

According to the preliminary results obtained, the use of sustainable cement with high content of ground granulated blast furnace slag overall produced a higher pore refinement and a reduction of absorption at 28 hardening days for all the mortars studied, independently of the aggregate used. In general, mortars which incorporated expanded cork and natural cork showed higher porosities and water absorption than the other series, for both cements studied. However, it would be interesting to follow the evolution of the microstructure and water absorption of these mortars with cork at later ages.

Author Contributions: Conceptualization, F.G.B. and J.M.O.; methodology, F.G.B. and J.M.O.; investigation, L.P., F.G.B. and J.M.O.; data curation, L.P., F.G.B. and J.M.O.; writing-original draft preparation, J.M.O.; writing-review and editing, L.P. and F.G.B.; supervision, F.G.B. and J.M.O.; funding acquisition, J.M.O.; This research is part of the work developed along the research stay of J.M.O. in the ISISE-Functional Performance research group at Department of Civil Engineering of University of Coimbra between May and July 2019, under the supervision of F.G.B.

Funding: The research stay of José Marcos Ortega at University of Coimbra was financially supported in part by University of Alicante. This work was partially funded through FCT-Foundation for Science and Technology, IP, within the scope of the R\&D Unit Institute for sustainability and innovation in structural engineering-ISISE (UIDP/04029/2020), and by the ERDF through the COMPETE 2020 program, Portugal 2020, under the project POCI-01-0247-FEDER-033990 (iNBRail).

Acknowledgments: The authors also wish to thank Cementos Portland Valderrivas S.A. for providing the slag cement III/B 32.5 N/SR used in this study.

Conflicts of Interest: The authors declare no conflict of interest.

\section{References}

1. Shi, C.; Jiménez, A.F.; Palomo, A. New cements for the 21st century: The pursuit of an alternative to Portland cement. Cem. Concr. Res. 2011, 41, 750-763, doi:10.1016/j.cemconres.2011.03.016.

2. Bijen, J. Benefits of slag and fly ash. Constr. Build. Mater. 1996, 10, 309-314, doi:10.1016/0950-0618(95)000143.

3. Thomas, M.D.A.; Scott, A.; Bremner, T.; Bilodeau, A.; Day, D. Performance of slag concrete in marine environment. ACI Mater. J. 2008, 105, 628-634.

4. Branco, F.G.; Godinho, L. On the use of lightweight mortars for the minimization of impact sound transmission. Constr. Build. Mater. 2013, 45, 184-191, doi:10.1016/j.conbuildmat.2013.04.001.

5. Belgas, L.; Branco, F.G. Cork concrete mechanical behavior under high temperatures. Int. J. Hous. Sci. Its Appl. 2013, 37, 207-215.

6. AENOR UNE-EN 197-1:2011. Composición, especificaciones y criterios de conformidad de los cementos comunes. 2000, 30.

7. ASTM ASTM C642-06 Standard Test Method for Density, Absorption, and Voids in Hardened Concrete 
2006,3

8. Escalante-García, J.I.; Sharp, J.H. Effect of temperature on the hydration of the main clinker phasesin Portland cements: Part II, blended cements. Cem. Concr. Res. 1998, 28, 1259-1274.

Publisher's Note: MDPI stays neutral with regard to jurisdictional claims in published maps and institutional affiliations.

(C) 2020 by the authors. Submitted for possible open access publication under the terms and conditions of the Creative Commons Attribution (CC BY) license (http://creativecommons.org/licenses/by/4.0/). 